\title{
Trio - Jogo Coreográfico: Função e expressão no ato performativo
}

\author{
Lígia Losada Tourinho \\ Universidade Federal do Rio de Janeiro - UFRJ, Rio de Janeiro/RJ, Brasil \\ E-mail: ligia.tourinho@gmail.com
}

\section{Resumo}

Reflexão sobre o processo de criação da Performance Trio, do Projeto Jogo Coreográfico, que realiza ações às quais a autoria é compartilhada com o público. O artigo apresenta o contexto do projeto para adentrar nas especificidades do processo de criação da performance e realizar uma reflexão a partir da Análise de Movimento Laban/ Bartenieff, tendo como principal lente o grande tema Função e Expressão.
Discussion about the Performance Trio, from Choreographic Game Project, which the authorship of this performance is shared with the audience. The article presents a contextualization of the project to discuss the process of creation of the performance based on a Laban Movement Analysis (LMA), supported by the theme Function and Expression.

Keywords

Choreographic Game. Laban Movement Analysis (LMA). System Laban/Bartenieff. Choreografic Composition. Authorship Shared with the Audience.
Jogo Coreográfico. Análise de Movimento Laban/ Bartenieff. Sistema Laban/Bartenieff. Composição Coreográfica. Autoria compartilhada com o público. 


\section{Jogo Coreográfico}

O Projeto Jogo Coreográfico foi criado em 2005 pela artista do movimento Lígia Tourinho e, desde então, segue uma trajetória de ações pedagógicas e atos performativos no campo da dança. É uma proposta interativa e divertida sob a estrutura e forma do jogo, a fim de compor danças que compartilham com o público a autoria do trabalho. A idéia surgiu como uma metodologia para a composição coreográfica e possui um aspecto performático que reúne espetáculos, performances, intervenções urbanas e residências coreográficas. Este artigo destina-se a discutir o processo de criação da performance Trio, desenvolvida pelas artistas Bruna Fiuza, Camila Fersi e Lígia Tourinho.

Trio foi criado na cidade no Rio de Janeiro, durante o ano de 2011. A pesquisa artística tinha como primeira intenção criar uma experiência solo do Jogo que pudesse ser performada por quaisquer uma das três artistas. Durante o processo de criação essa ideia de solo perdeu o sentido para a equipe. Optaram por criar um jogo com a presença das três performando. Os ensaios começaram com a experimentação livre dos elementos estruturais performativos do Projeto Jogo Coreográfico. A seguir será apresentada uma contextualização do projeto e uma descrição da estrutura base do Jogo para, em seguida, serem apresentadas as especificidades do processo do Trio.

\section{Projeto Jogo Coreográfico}

O "Jogo Coreográfico" teve origem durante as experiências em sala de aula da coreógrafa Lígia Tourinho. O objetivo era permitir que os alunos experimentassem improvisação e composição com conteúdos variados, conectando aspectos funcionais do movimento com a expressão da dança.

A dificuldade dos alunos em perceber o outro e se relacionar com o ambiente durante as danças era evidente. Eles estavam muito preocupados com os movimentos realizados e suas imagens, não pensavam na cena a partir da tríade do fenômeno cênico: artistas dentro da cena, artistas fora da cena e público. No geral, o foco dos estudantes estava em sua execução do movimento.

O Jogo Coreográfico surgiu como um jogo de composição para a sala de aula. A arte da composição da dança tem sua origem na comunhão da humanidade com o universo; composição de dança não é a capacidade de criar formas somente, mas a arte de criar relações, de articular conteúdos de movimento e criar narrativas.

O grande tema labaniano Função e Expressão atende a discussão destas questões apresentadas. O movimento funcional está relacionado à mecânica do movimento, por exemplo, às partes do corpo se movem em uma ação. O movimento expressivo também diz respeito sobre qual parte do corpo está se movendo em qual ação, e nos conduz a refletir sobre como e por que você está se movendo, que conexões são estabelecidas neste ato. A expressão é a "sensação", o sabor, o significado dentro do movimento ou mesmo seu infinito intangível, impossível de ser traduzido em palavras. Refletir sobre as relações entre Função e Expressão neste Jogo, nos permite adentrar na sua essência: na articulação de conteúdos da dança, na capacidade de abordar o movimento a partir de sua própria linguagem e acessar os aspectos intangíveis da expressividade. Neste artigo, apresenta-se como a lente principal para a realização da Análise de Movimento Laban/ Bartenieff.

Ao perceber a qualidade poética deste jogo em contexto pedagógico, foi constatada sua potência performática. Desde então o Jogo da sala de aula se desdobrou em algumas performances que tiveram grande impacto e aderência na cena nacional de dança. Trilharam significativa trajetória nacional e internacional, percorrendo todas as regiões do Brasil e as cidades de Montevidéu, do México e Nova York. O Jogo Coreográfico foi abordado em livros didáticos da editora Abril, destinados às escolas do ensino fundamental nos estados de São Paulo e Pernambuco, e também foi questão de concurso para professores licenciados em dança no estado de São Paulo. A performance Jogo Coreográfico já foi realizada 
pela Pulsar Cia de Dança (RJ) e pelo Grupo Acupe (PE). O projeto foi convidado por importantes festivais brasileiros, como a Bienal de Dança do SESC (2009) e recebeu fomentos como o IBERESCENA 2012, Prêmio Funarte Petrobrás Artes Cênicas na Rua 2010, Prêmio Funarte Petrobras Klauss Vianna 2007, Edital Ciranda nas Escolas 2008 (SEC-Educação/ Prefeitura do Rio de Janeiro), Convênio Banco do Brasil/ UFRJ. Foi apresentado na ICKL Conference (International Council of Kinetography Laban - 2009) e na "Celebração Internacional Laban 2008 -Artes cênicas e novos territórios", no Rio de Janeiro.

$\mathrm{Na}$ imagem a seguir (figura 1) pode-se verificar a cronologia das obras realizadas pelo projeto:

Figura 1 - Linha do Tempo Jogo Coreográfico.

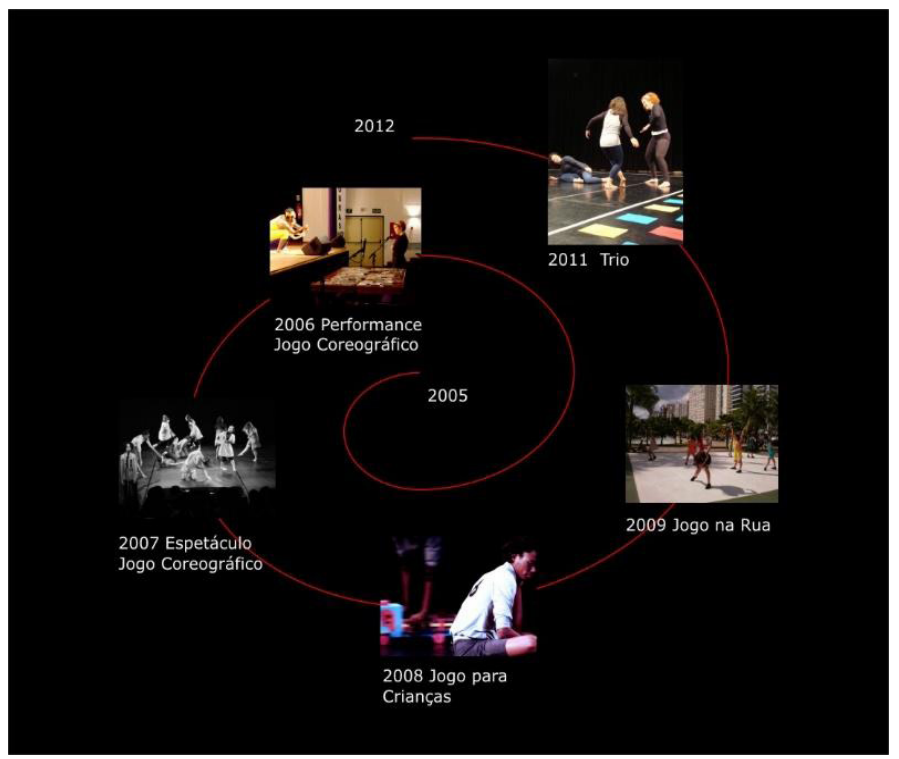

Fonte: Designer: Tiago Primo

\section{- Como funciona o Jogo: Função e Expressão - a estrutura comum à sala de aula e à cena}

O Jogo Coreográfico, como diz o nome, é um jogo de fazer danças com estrutura espacial e regras definidas. O Espaço Cênico é delimitado visivelmente: seja por linóleo, crepe ou fita colorida. Em frente à área cênica, há uma mesa com $C D$ s variados e um equipamento de som com cabos disponíveis para uso. Há também dois microfones que determinam o espaço que deve ser ocupado pelo Coreógrafo.
Todos os artistas nas performances são identificados com facilidade e iniciam o Jogo do lado de fora do Espaço Cênico. Existem três tipos de funções no jogo: Intérpretes, Coreógrafos e Público. Geralmente os jogadores podem transitar nas três funções. Ou seja, podem performar, coreografar (propor danças para serem performadas) ou contemplar as danças que estão acontecendo.

Quando o Jogo acontece na sala de aula, os jogadores passam pelas 3 funções. Quando o Jogo vira performance, geralmente os artistas jogadores passam pelas 3 funções e o público pode, além de contemplar as danças, ser convidado somente a coreografar ou a coreografar e dançar.

Nos formatos performáticos, há sempre uma primeira parte de explicação do Jogo. Geralmente, só os artistas jogam. Esta parte é exemplar e, além de revelar a funcionalidade do jogo, compartilha com o público as nomenclaturas do Jogo e da dança e conteúdos de movimento, evidenciando uma direta relação entre Função e Expressão.

$\mathrm{Na}$ segunda parte, o público é convidado a participar como Coreógrafo e/ ou Intérprete. A participação do público sempre foi espontânea, uma iniciativa individual, as pessoas não são nem convocadas e nem constrangidas à interagir.

A maneira de jogar é de captura rápida.

Os artistas na função de Performers estão preparados para agir e realizar algumas funções: caminhar, pausar e desenhar livres pelo espaço; ações simples como sentar, levantar, olhar um ponto, entre outros. Cada Jogador Intérprete possui uma partitura coreográfica. Eles estão preparados para imitar uns aos outros a partir de dinâmicas de coro e corifeu.

O Coreógrafo é aquele que propõe verbalmente as danças, ele pode combinar livremente as possibilidades de movimento dos Intérpretes. Ele verbaliza os conteúdos, criando uma estrutura para o surgimento das danças, numa dinâmica fluida entre a funcionalidade do movimento e sua expressividade (conforme figura 2). 
Figura 2 - Performance Jogo Coreográfico, Rio de Janeiro.

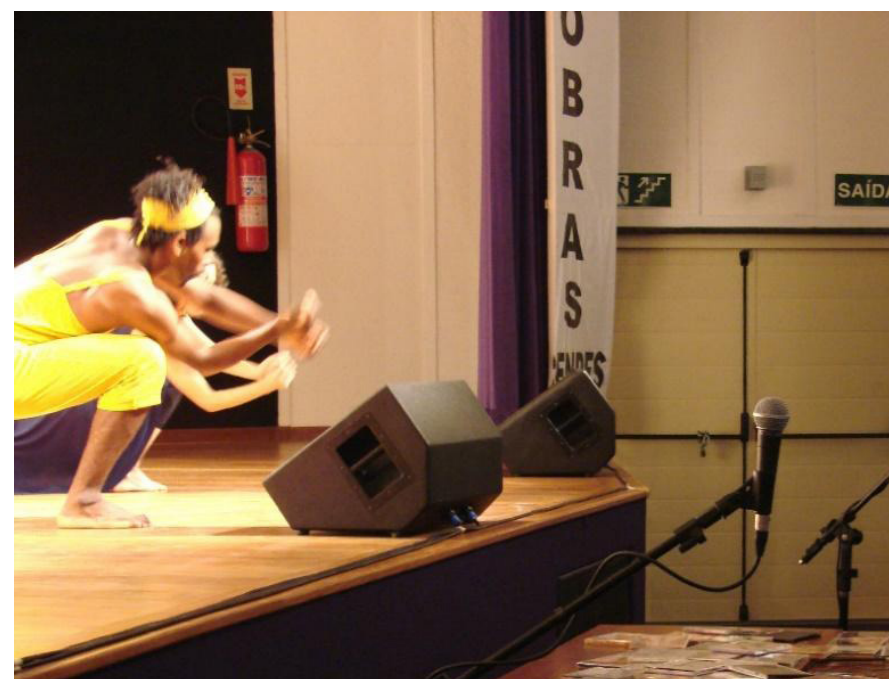

Fonte: Foto de Thalia Fersi

A coreografia é concebida como as leis que determinam o movimento inscrito no espaço e o Jogador Coreógrafo é aquele que cria essas leis na área cênica dentro de um prazo. Isso significa que a coreografia está criando relacionamentos. O Intérprete performa a proposta do Coreógrafo. Ele não é uma marionete, mas o agente de suas ações. Quando os artistas e os alunos experimentam essas funções, vivenciam a complexidade de se relacionar. Experimentam a ambivalência entre ser sujeito e veículo da arte: como sujeito, agem de acordo com as indicações estabelecidas e preenchem as lacunas da proposta coreográfica estabelecida; como veículo, agem de acordo com a cena e as ideias do Coreógrafo.

O Jogo Coreográfico apresenta uma estrutura interativa que permite que os jogadores lidem com os aspectos constituintes da dança a partir da materialidade da linguagem do movimento e da perspectiva de princípios, tais como: A composição da dança sendo concebida como um ato íntimo e sua pesquisa e exploração só podem ser alcançadas pela intensa prática coreográfica, a partir do suor produzido dentro das salas de ensaio (BLOM; CHAPLIN, 1942). A construção das artes do espectáculo ocorre coletivamente e para alguém. Até uma per- formance solo é produto de um diálogo entre si. Não é apenas uma dançarina, uma barra e um espelho (LABAN, 1978). O jogo é caracterizado como atividade livre, conscientemente fora da vida cotidiana, como sendo "não grave", mas, ao mesmo tempo, é capaz de absorver o jogador intensa e totalmente. $O$ jogo é mais antigo que a cultura. Os animais sempre brincaram; é mais do que uma função biológica ou fisiológica. O jogo é um atributo da vida (HUIZINGA, 1995). O jogo dramático não é a pedagogia das Artes da Cena, mas o fenômeno do jogo é o fundamento da relação estabelecida entre os artistas, a equipe e o público. O jogo é fundamento, princípio e metodologia não apenas para o teatro, mas também para as artes do espectáculo (LOPES, 1998). O movimento é linguagem e as complexidades do conteúdo explorado durante o Jogo Coreográfico partem da Análise de Movimento Laban/ Bartenieff.

\section{Figura 3 - Jogo Coreográfico com Cia. Acupe,} Recife, Brasil.

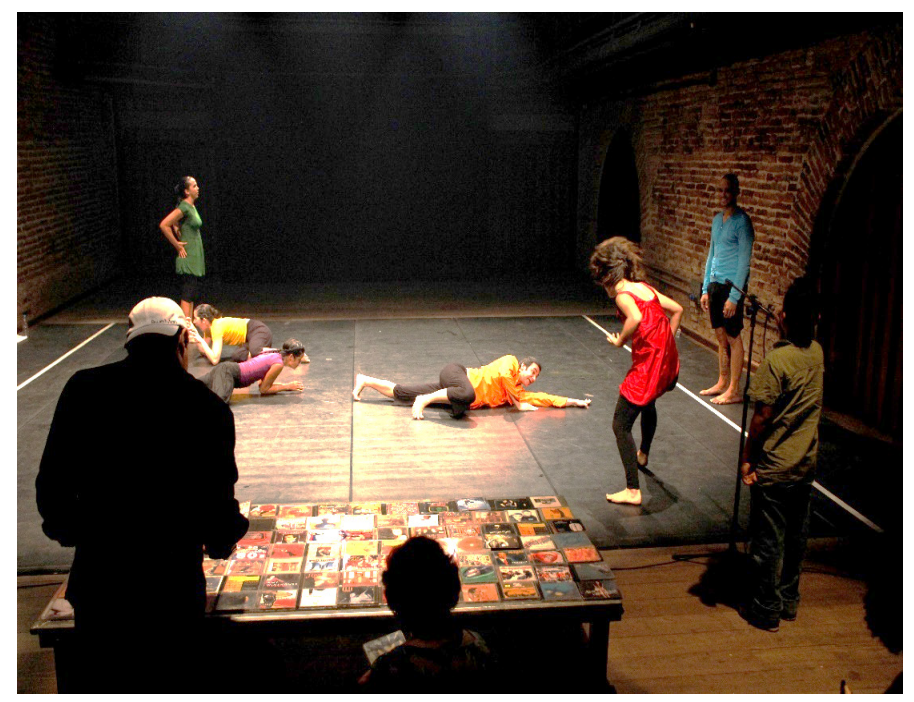

Fonte: Foto de Rodrigo Moreira. 
Figura 4 - Jogo Coreográfico com a Pulsar Cia. de Dança, Rio de Janeiro, Brasil.

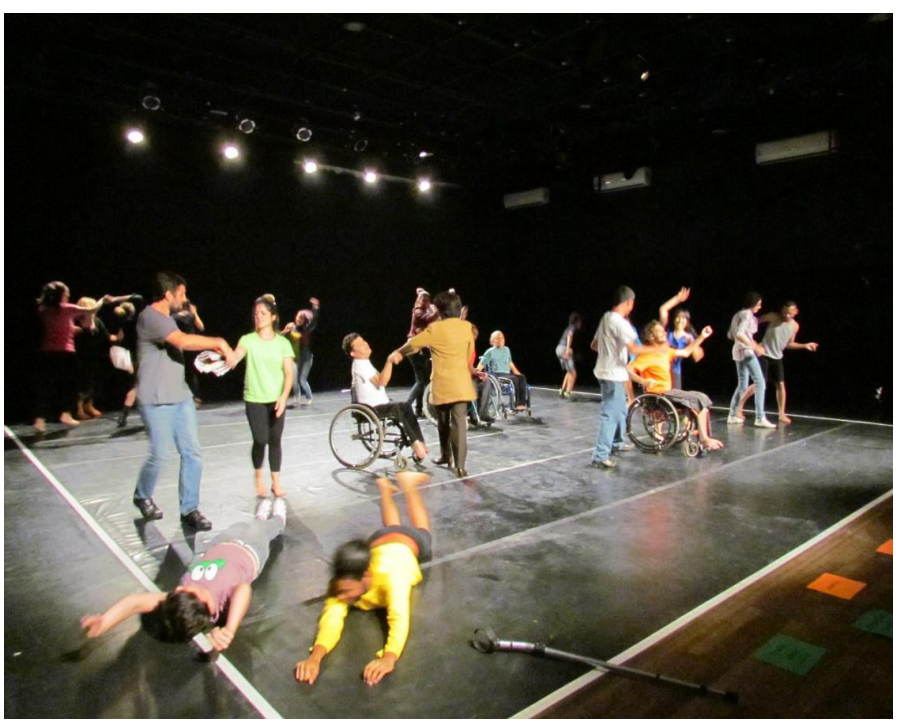

Fonte: Fotógrafo desconhecido.

A estrutura do jogo faz com que a proposta coreográfica exista como um evento (conforme figuras 3 e 4). Faz com que a imprevisibilidade esteja sempre em evidência e a experimentação coreográfica seja a situação, desconectando a perspectiva da cena como uma repetição da performance. Isso faz o jogador voltar-se para o processo e não para o resultado final, atento ao fluxo entre Função e Expressão.

As versões performáticas do Jogo são estruturadas sob a perspectiva da dança contemporânea: todo movimento pode ser conteúdo de dança. É um experimento sobre a democratização da dança, tornando-a acessível a todos os indivíduos e suas histórias corporais. Não há elegibilidade de um modelo corporal, porque este projeto não privilegia uma técnica ou estética da dança em detrimento das outras. É uma estrutura de exploração investigativa aberta a qualquer modo de mover e poética.

O Jogo Coreográfico, na versão pedagógica e performática, explora dinâmicas de coro e corifeu, diretamente inspiradas na Dança Coral de Laban: uma dança coletiva sem preocupação com o ser profissional ou social no sentido clássico. As pessoas são integradas para apreciar e compartilhar o movimento e, juntas, aprendem a melhor apreciá-lo. Laban
(2001) já dizia que somos um coral em movimento. O Jogo também foi influenciado pelas questões relativas ao movimento de reteatralização, pelas discussões sobre performance e recuperação da ideia da cena como celebração, como ritual, como evento. Foi intrinsecamente influenciado por discussões sobre as novas dramaturgias, as dramaturgias do corpo e o teatro pós-dramático. Experimenta as investigações no campo da improvisação e interatividade, buscando novas formas de estabelecer relações com a criação, a composição de cenas e o público.

\section{Figura 5 - Jogo Coreográfico na rua, Rio de Janeiro.}

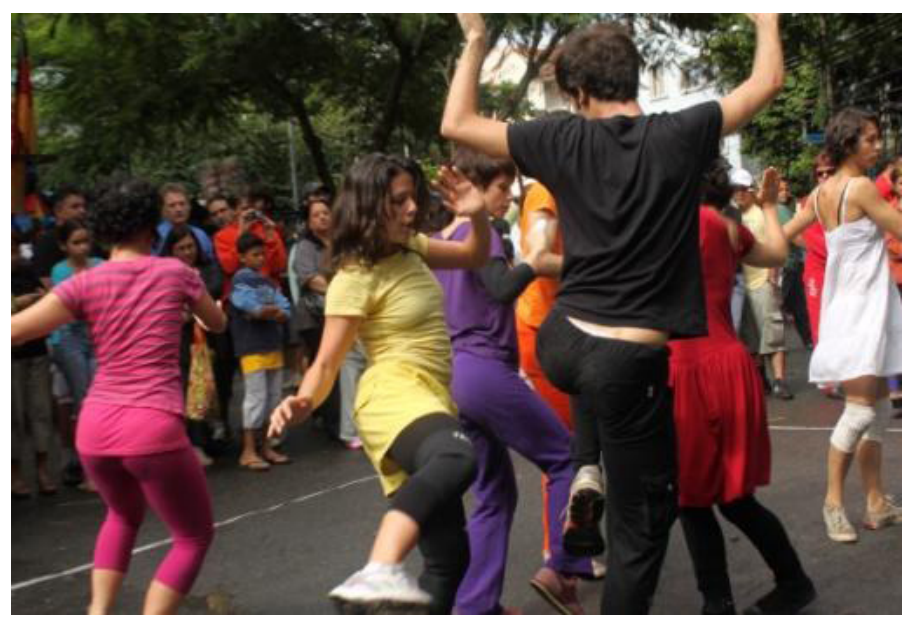

Fonte: Foto de Júlia Tourinho.

A dramaturgia do Jogo é construída durante a performance. É um ato performativo que aborda a composição em tempo real (conforme figura 5). Conteúdos de movimento são propostos para iniciar as danças, e estas são desenvolvidas a partir desses motivos de movimento. O conhecimento e as reflexões são derivados da experiência e as obras de dança são discursos poéticos do, sobre e para o mundo. É impossível desassociar sua prática de uma ética da vida, de um conjunto de crenças sobre o que é realidade, que integram nossos contextos e constituem o que chamamos de nosso próprio mundo.

Através dos tempos, o conhecimento sobre dança foi estabelecido a partir de processos de criação - criando protocolos. Abordar a dança sob 
essas perspectivas é reconhecer a diversidade de pontos de vista que atravessam seus modos de fazer. Quando falamos sobre processos de criação em dança, entendemos que não apenas a dança, mas também as ações de pensar, conceituar e escrever fazem parte da dança como uma experiência.

Este é um jogo para praticar a linguagem do movimento e a gramática da dança. A maneira de acessar esta gramática é a Análise de Movimento Laban/ Bartenieff. É ao mesmo tempo pedagógico e introdutório, como também uma maneira de pesquisar e desenvolver novas idéias, imagens e possibilidades de dança. É sobre a relação entre Função e Expressão, mas, simultaneamente, durante o jogo, outros grandes temas podem surgir, em uma segunda camada - Mobilidade e Estabilidade, Ação e Recuperação e Interno e Externo.

Cada processo de trabalho, composição ou treinamento tem uma vida própria e possivelmente articula Função e Expressão de acordo com a necessidade e os valores do próprio processo. Os processos de criação têm uma força existencial. Revelam características, condições e necessidades dos artistas. Quando são agenciados sob forma de perguntas, os processos começam a manifestar sua presença aos artistas, assim como os artistas criam seus trabalhos a partir de suas perguntas e desejos. Talvez, por esse motivo, falar sobre processos criativos também seja falar sobre o invisível, ou sobre o Mundo do Silêncio, como dizia Laban.

$O$ início de um processo criativo pode ter diferentes razões; pode ser definido durante o processo de criação, como Kerkhove (1997) denominou dramaturgia do processo, ou a partir de uma estrutura pré-estabelecida, denominada pela autora como dramaturgia de conceito. As possibilidades de criar dramaturgias são plurais. O Jogo Coreográfico evidencia estas experiências plurais que são as dramaturgias de processo e a composição coreográfica em tempo real.

Existem tantas formas de composição, como os artistas forem capazes de criar, já dizia Laban (2001) em Uma Vida para a Dança. O mundo mudou profundamente desde o início do século XX, não apenas o mundo, mas também a humanidade, artistas e narrativas. A prática de composição em dança e da construção dramatúrgica permitem ao artista observar o mundo e expor suas idéias, perguntas, motivações, e outras possibilidades de estruturas cênicas. A coreografia não é uma combinação de etapas; tem origem no chorus, na alegria ancestral de honrar os deuses, no pulso da vida.

Ao refletir sobre Função e Expressão no processo de composição coreográfica do Jogo, estamos também discutindo formas de lidar com o imaginário. Como a relação entre Função e Expressão no movimento e na Dança podem nos auxiliar a ampliar a imaginação dos artistas e contribuir para o processo formativo e para a recepção do público? Nossa construção de imagens ainda é modelada de maneira arbitrária pela sociedade. É necessário repensar as estruturas. Por exemplo, as salas de aula das escolas ainda estão organizadas em filas, reforçando o modelo mecanicista da educação formal. Nossa imaginação é dominada pela televisão, publicidade, personagens da Disney, Mc Donald's e cinema de Hollywood - guiados por uma métrica catártica moralista e aristotélica. A questão pós-dramática é mais complexa do que romper com o drama.

A resposta pode ser pensar a prática da composição e a formação de novos coreógrafos e artistas de experiências em dança que estimulem as singularidades, desejos e impulsos de expressão. O objetivo não é a reprodução de modelos, mas a construção de poéticas.

\section{Trio}

A pesquisa artística que culminou na performance Trio foi iniciada a partir deste contexto apresentado. No início do processo o objetivo era criar um Jogo Solo. As artistas entravam na sala de ensaio e começavam a experimentar e alternar as funções do Jogo. Concomitantemente, começaram a listar os conteúdos e questões relativas aos movimentos geradores e motivadores para a criação e composição das danças, criando elos e conexões entre Função e Expressão. 
A metodologia de criação do Trio foi desenvolvida em reuniões semanais de quatro horas. A experimentação foi organizada em etapas e gradualmente essas etapas se tornaram um ritual de trabalho: aquecimento individual e em grupo, conexão - zona de contaminação, tiros de improvisação e discussão final. Havia uma progressão clara entre o interesse pela funcionalidade do movimento e sua migração para a expressividade (figura 6).

$\mathrm{O}$ aquecimento individual e em grupo consistiu em um momento pessoal de aquecimento e chegada ao espaço da criação. Era uma etapa de experimentação dos Fundamentos de Bartenieff: um momento para explorar os seis básicos, seu fraseado e uma abordagem livremente das categorias CORPO, ESFORÇO, ESPAÇO e FORMA.

O estágio seguinte visava encontrar a conexão entre o grupo e explorar uma zona de contaminação, um espaço de relação. Nesta fase, as artistas exploravam jogos de improvisação nos quais os conteúdos de movimento listados eram compartilhados sem o uso de palavras, mas apenas a partir da linguagem do movimento e da improvisação. A experimentação destes conteúdos conduziram as artistas à criação de um cardápio de conteúdos usados na performance.

A penúltima parte do ensaio consistia nas cenas de improvisação (conforme figuras 7, 8 e 9). Nesta fase, estavam totalmente comprometidas com o ato performativo, improvisavam sem dar tempo para racionalizar as propostas, de forma rápida e direta, por isso chamavam de tiros de improvisação. Os primeiros tiros se davam sob a forma clássica do Jogo, acionando as funções de Coreógrafa, Intérprete e Público. Cada uma experimentava cada uma destas funções. Os seguintes eram livres, uma apresentava uma imagem, a outra improvisava e a outra assistia.

Essa estrutura de ensaio almejava criar dinâmicas solo, buscando atender ao propósito inicial do processo. No final dos ensaios, anotavam os conteúdos de movimento, imagens e experimentavam tecer relações entre a funcionalidade dos conteúdos e a expressividade das danças criadas.
Figura 6 - Ensaios do Trio.

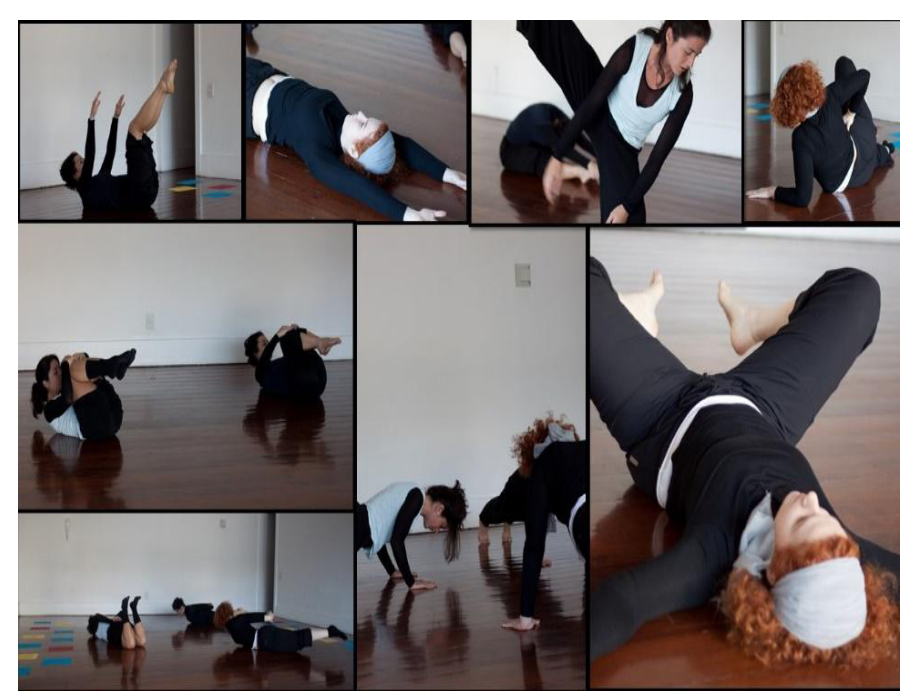

Fonte: Fotos de Júlia Tourinho.

\section{Notas dos cadernos das artistas:}

Queda expansão achatamentos planos volutas saltos na sagital giros torções desequilíbrio espaço interno enigma paradoxos são conflitos campo de conexão caminhadas pausas esculpir silêncio palavra fala espaço fala informativa fala visceral estabelecer a convenção experiência desenhos livres pelo espaço esculpir os desenhos caminhadas e pausas cada mudança tem que ser falada até o que é pequeno? Falar projetado e objetivo levar o público a uma dança coral de ações simples público entra na fronteira divertido desenhar livre pelo espaço contaminação região do silêncio cena livro branco não há erro espaço do silêncio fruição pelo movimento treinamento para improvisar é viver filosófico concretude/ imaginação território frouxo movimento memória pensamento técnica imaginação corpo esforço espaço forma ações básicas do corpo abc introdutório bess locomoção parar transferência de peso mudança de apoio girar pular espalhar recolher dobrar desdobrar estender contrair em cima centro embaixo níveis ações trazem o espaço em dupla o espaço se resolve melhor girar desdobrar pontos de conforto música menos é vale tudo mas não é para colocar tudo não é ditado o jogo não precisa ser multifocado afinidade com urgência e multifocado palavras sugestões do chef mesa porta roda livre contido amarelo azul e vermelho espaço tensão estrutura locomoção mudança de apoio com peso forte o tema imagem tema conteúdo tangível e in- 
tangível espaço dimensão direita esquerda frente atrás cima baixo plano combinação de duas combinação de três tempo lento espalhar recolher roda octaedro forma fluida crescer diminuir alargar estreitar encher esvaziar eixo vertical eixo horizontal plano vertical porta ação recuperação função expressão experimentar os básicos como ação do corpo articular muscular 11 sistemas corporais arredondado espiralado piramidal agulhado verbos substantivos achatados temas imagens bush vai ao balé dando o bote uma noiva abandonada no meio de um tiroteio articulação de ideias em movimento trio anima ritual do trio metáforas palavras coloridas papéis trio performance queda expansão achatamentos planos livre pelo espaço contaminação região do silêncio cena"...

Figura 7 - Tiros de Improvisação: Bruna Fiuza e Lígia Tourinho.

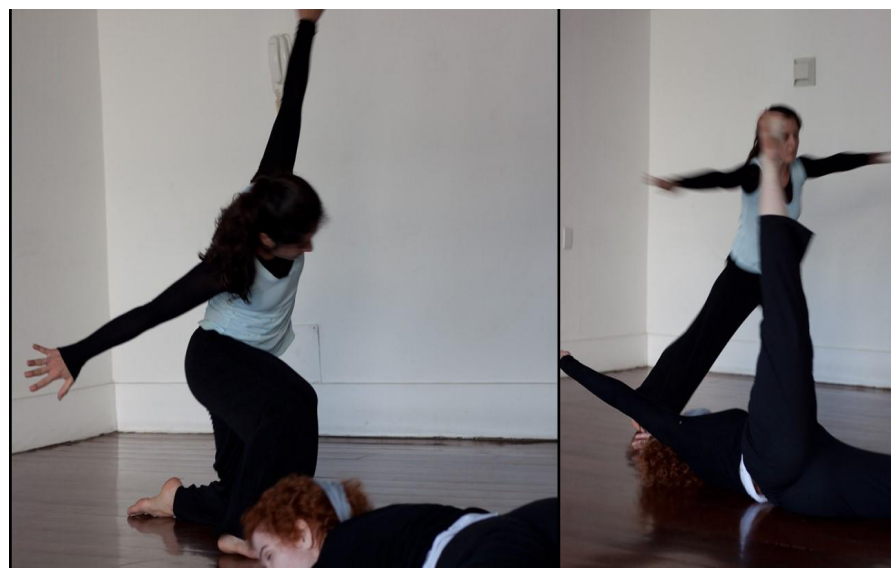

Fonte: Fotos de Júlia Tourinho.
Figura 8 - Tiros de Improvisação: Camila Fersi e Lígia Tourinho.

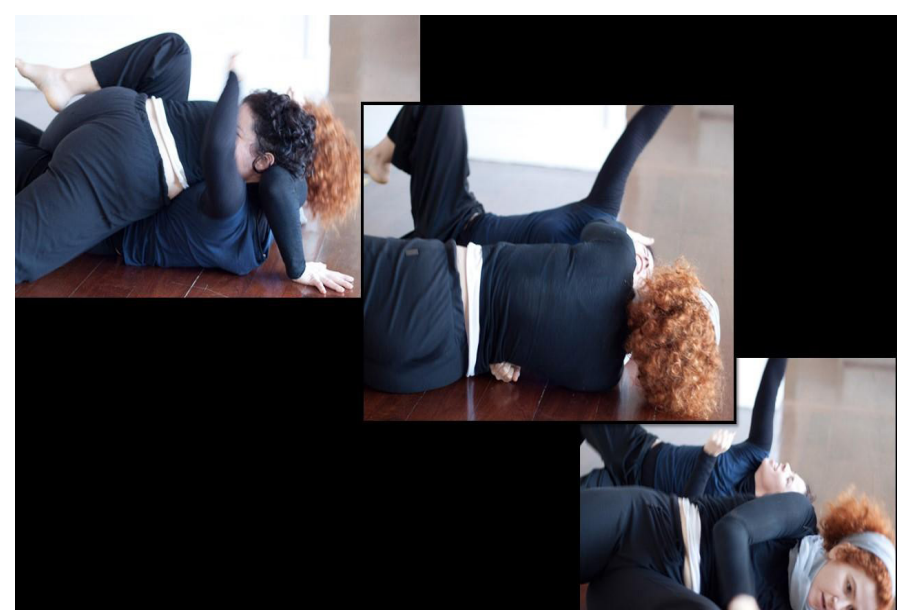

Fonte: Fotos de Júlia Tourinho.

Figura 9 - Tiros de Improvisação: Bruna Fiuza e Camila Fersi.

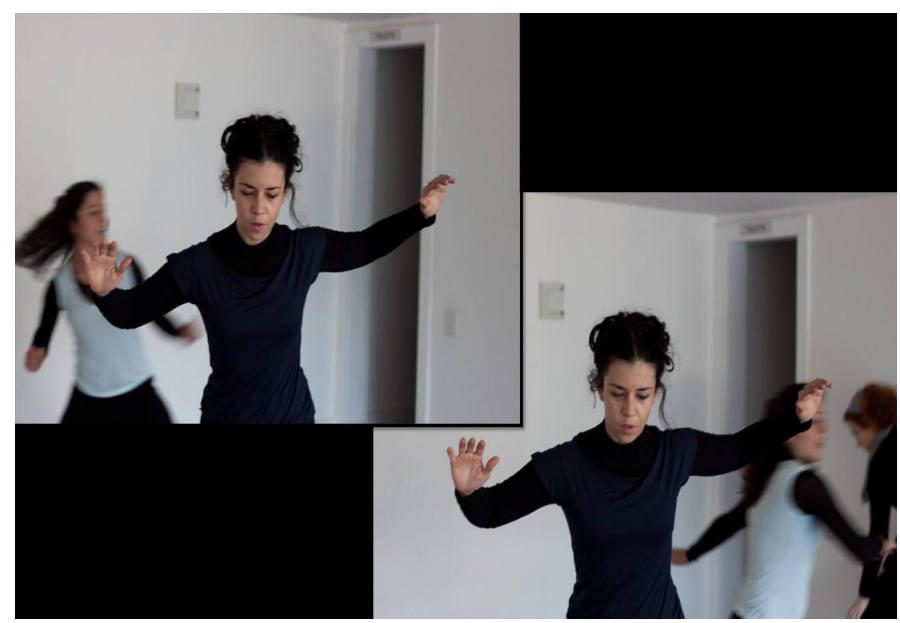

Fonte: Fotos de Júlia Tourinho.

Após cinco meses de trabalho toda a pesquisa foi organizada em um ensaio aberto para a Mostra Encontros de Improvisação - ato I no Teatro Cacilda Becker em Julho de 2011. O grupo organizou uma estrutura de apresentação das questões da pesquisa em trio (conforme figura 10). Ao final desse ensaio aberto constatou-se que havia ali uma performance: Trio - um jogo de fazer danças motivado por conteúdos temáticos que explora as potências do corpo estrutura, sua relação com o espaço, qualidades e formas, estabelecendo uma relação de diálogo com a plateia e compartilhando 
esses conteúdos de improvisação, criação e composição em uma relação espontânea e democrática de interatividade e coautoria da cena com o público.

Figura 10 - Trio, Rio de Janeiro.

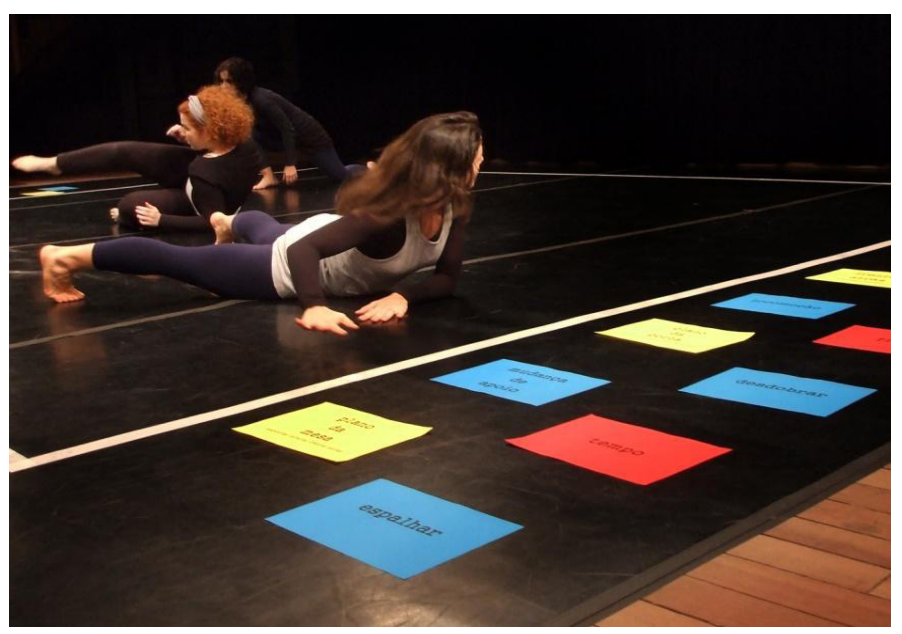

Fonte: Foto de Thalia Fersi.

O Trio acontecia em um espaço quadrado ou retangular delimitado por uma fita crepe e com palavras coloridas na lateral. As palavras/motivos de movimento, revelavam os conteúdos recorrentes anotados nos cadernos de ensaio. A dramaturgia da performance começava com o encontro com a plateia, nele as performers se apresentaram e começaram a dançar - uma dança que tem como suporte a pesquisa sobre conexão e zona de contaminação. Aos poucos alternavam entre as funções de Intérpretes, Coreógrafas e Público. A medida que as palavras coloridas eram verbalizadas pelas Coreógrafas, eram recolhidas pelas mesmas e colocadas na frente do espaço de cena. Quando todas estavam no proscênio, era o sinal para a finalização da primeira parte do Jogo. Neste momento as performers convidavam as pessoas do público a jogar como coreógrafos.

As palavras eram como "sugestões do chef" (conforme figura 11), não precisavam ser utilizadas, ficavam como possibilidade. Correspondiam a conteúdos oriundos das categorias CORPO, ESPAÇO, ESFORÇO e FORMA. São auto-explicativas, dispensam um conhecimento prévio do campo labaniano. Possuem potência dramatúrgica e au- xiliam o público a reconhecer e a iniciar uma experiência lúdica sobre a linguagem do movimento, em termos de movimento, funcionando como um portal de acesso a conteúdos próprios da linguagem da dança, articulando Função e Expressão.

A escolha das palavras era uma forma de acessar as categorias do Sistema Laban. O público não precisava ter esta consciência, mas as Intérpretes sim. Elas introduzem a Análise de Movimento Laban. $\mathrm{Na}$ categoria CORPO, elegeram as Doze Ações do Corpo para acionar a relação entre o Corpo Inteiro e suas Partes e convidar ao engajamento com o grande tema Mobilidade e Estabilidade. Em ESPAÇO, as palavras mostravam Direções, Planos e Diagonais. Ao mover, traziam afinidades de Esforço e Espaço $e$, às vezes, Escalas labanianas ou pessoais. Em ESFORÇO, cada Fator de Movimento se tornou uma palavra, as pessoas poderiam fazer combinações, se quisessem. Em FORMA, escolheram as formas básicas. Os Modos de Mudança de Forma e a Forma Fluida apareciam através das Formas Básicas.

A performance Trio seguiu em turnê, realizou apresentações no Rio de Janeiro, Belo Horizonte, São Paulo e em Montevidéu, no Uruguai, conforme figuras 12 e 13).

Figura 11 - Palavras do Trio.

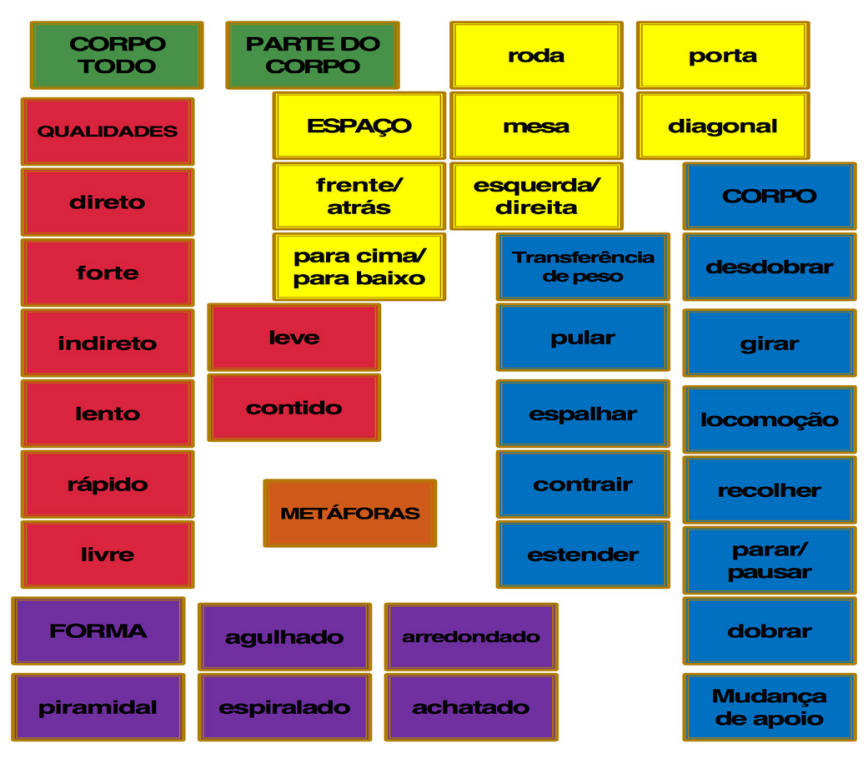

Fonte: Arquivo pessoal. 
Figura 12 - Trio, Rio de Janeiro.

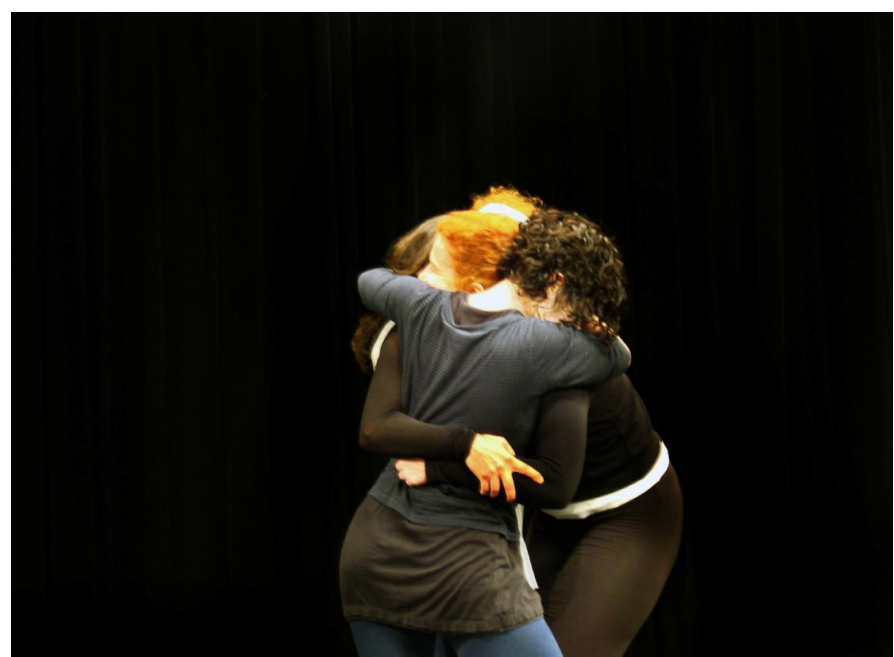

Fonte: Foto de Thalia Fersi.

Figura 13 - Trio, Rio de Janeiro.

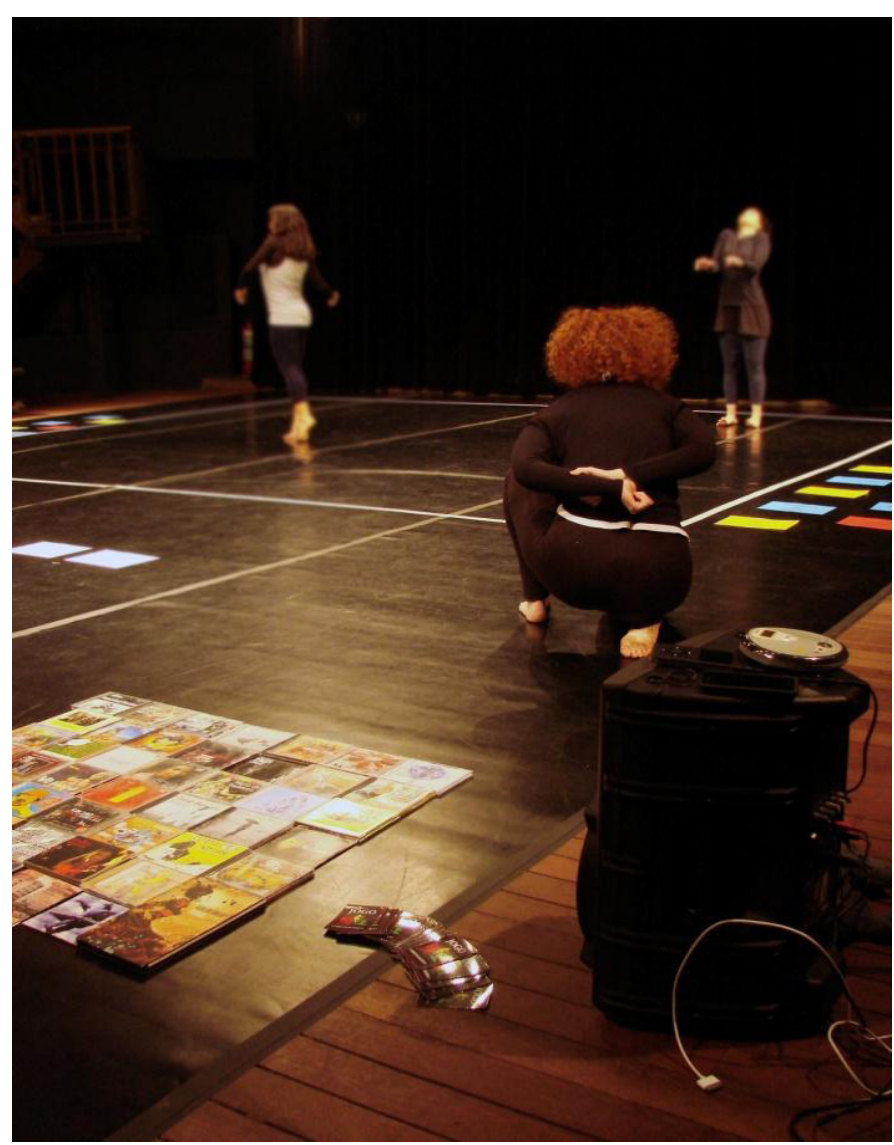

Fonte: Foto de Thalia Fersi.
- Análise Laban/ Bartenieff: reflexão sobre um trecho da obra para evidenciar as articulações entre Função e Expressão

Com o intuito de evidenciar como os agenciamentos entre Função e Expressão se dão no ato performativo de Trio, este texto se conclui com a Análise Laban/Bartenieff (conforme figuras 14 e 15) completa de um fragmento de 60 segundos de uma das apresentações de Trio, realizada no aniversário de 10 anos do Centro Coreográfico da Cidade do Rio de Janeiro". Neste momento Lígia Tourinho performa como Coreógrafa e Bruna Fiuza e Camila Fersi, como intérpretes.

$\mathrm{Na}$ descrição da fala da Coreógrafa a seguir, é possível perceber os conteúdos de movimento (destacados em negrito) presentes e como se transformam durante a ação (nos Motifs $^{2}$ ), correlacionando Função e Expressão:

Bruna, continue desenvolvendo um desenho com os braços e vai deixando que os braços te levem a girar e o resto do corpo acompanha o movimento dos braços. Camila, sempre construa diagonais em relação à Bruna. Vai criando diagonais no seu corpo que estão em relação à Bruna. E vai percorrendo essa diagonal e trabalhando aproximações e afastamentos da Bruna. (TOURINHO, 2018).

1 Link do vídeo: https://youtu.be/HWX-AvrANtE. Tempo de análise: 60 segundos, de 1:11 to 2:11.

2 Os Motifs foram feitos pela autora do texto, como pré-requisitos para a obtenção de sua certificação como Analista do Movimento Laban/ Bartenieff e serviram como suporte para análise de movimento durante o processo de circulação da performance Trio. São conteúdo chave para a reflexão proposta por este artigo, garantindo a realização de uma Análise de Movimento Laban/ Bartenieff completa. 
Figura 14 - Motif horizontal.

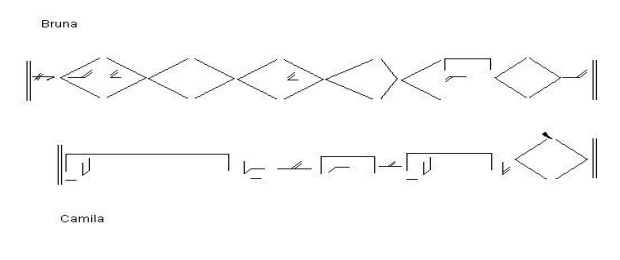

Fonte: Arquivo pessoal.

Figura 15 - Motif Vertical.
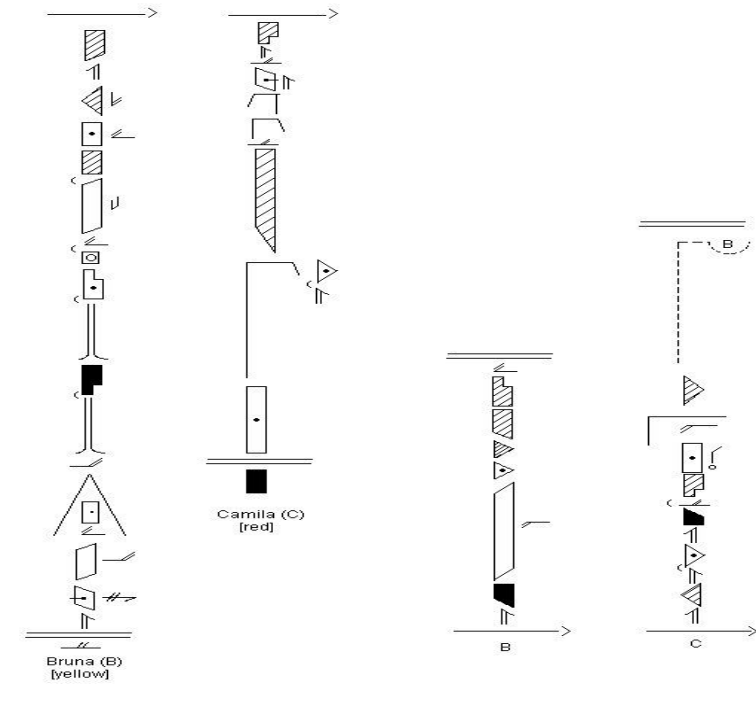

Fonte: Arquivo pessoal.

Na primeira parte da dança, as sugestões da jogadora coreógrafa pertencem à categoria CORPO. A indicação era usar os braços para fazer o corpo girar. Uma parte do corpo faria o corpo inteiro se mover girando, uma das Doze Ações Básicas do Corpo foi escolhidas como conteúdo e motivo de movimento.

A primeira performer, Bruna, começou a se mover e imediatamente integrou ESFORÇO e ativou Modos de Mudança de Forma, usando Forma Fluida, Movimentos Direcionais e Esculpidos. Analisando o Motif, é possível ver como as sugestões de palavras ativam além da sua, outras categorias de movimento. Como o movimento funcional ao ser preenchido de poesia acessa as categorias ESFORÇO e FORMA.

A Jogadora do Coreógrafa estruturou os conteúdos de movimento para a dança, organizando sua coerência funcional, enquanto as Intérpretes completavam engajando expressividade, evidenciando claramente o grande tema Função e Expressão.

A segunda parte das sugestões da Coreógrafa eram sobre ESPAÇO. O público foi convidado a observar como Camila se relacionava com Bruna. Camila usou suas Instruções da categoria CORPO para fazer Conexões Espaciais com Bruna, numa evidente relação CORPO-ESPAÇO. Geralmente, usa-se uma das Chaves de Referência, Corpo ou Espaço. Nessa situação, ela usou as duas chaves. O Público foi convidado a observar as Direções presentes no corpo de Camila, tendo seu Centro como Referência, e as Diagonais que foram feitas entre Camila e Bruna, observando o Espaço como referencial. Quando a coreógrafa sugere que Camila se aproxime e se afaste de Bruna, ativa as palavras Frente/ Trás, a Dimensão Sagital, para conectar CORPO e ESPAÇO, direcionando uma intérprete a outra.

Quando Camila começou seu movimento, ela usou as conexões CORPO-ESPAÇO para ativar a FORMA. Esta é uma característica dessas jogadoras intérpretes, elas recorrentemente acionam Modos de Mudança de Forma. As categorias usadas pela Coreógrafa para a dança eram CORPO e ESPAÇO, mas as intérpretes usaram FORMA para ativar a ESFORÇO.

Existe uma conexão importante entre a palavra como motivação e o que se pode desdobrar em movimento. É uma maneira de analisar, fazer conexões e desenvolver idéias e danças. Integrando as imagens, as notas dos ensaios, as palavras e os motivos, esta pesquisa artística pôde crescer e ser desenvolvida.

Bruna está dançando com todo o corpo envolvido, mais móvel. Camila está misturando gestos e ações com o corpo inteiro, mais estável. Mobilidade e Estabilidade podem ser observadas como um grande tema secundário, a partir da diferenciação entre as Intérpretes.

O processo de composição do Trio e principalmente suas palavras têm um potencial de ação que pode ser articulado de diferentes maneiras ao exercício e à prática da composição coreográfica. No Jogo Coreográfico a própria ação performativa é também 
pedagógica e possibilita a pesquisa em composição através da experiência. A partir de sua estrutura, é possível investigar questões de movimento e composição em dança simultaneamente. A experiência deste Jogo é organizada a partir de uma tríade, que se relaciona: AÇÃO, VerbalizAÇÃO e ApreciAÇÃO.

A composição dá vida à imaginação, é a imagem em ação! Nesse processo, agir, nomear e apreciar são os principais fundamentos de jogo. Nomear o que acontece não é decodificar o mundo do silêncio e nem transformar o intangível em tangível. É encontrar e escolher um vocabulário adequado para a linguagem do movimento e ser capaz de lidar com o intangível, compreendendo as palavras como parte do processo, porque elas são incapazes de explicar tudo. A palavra não é necessariamente a linguagem mais importante na polifonia da cena. O exercício de nomear nos permite encontrar outras maneiras de lidar com a palavra e o movimento.

O verbo apreciar tem a idéia semântica de observar algo com cuidado ou entender o quão útil é algo para emitir uma opinião, avaliar, determinar um valor ou até estimar. A apreciação também é uma atividade de fruição, intangibilidade, acesso ao Mundo do Silêncio e não causalidade, extremamente importantes para a prática artística.

O Jogo possibilita a experimentação das funções da tríade cênica (intérprete, diretor e público); é uma experiência complexa. Os Coreógrafos citam seus motivos de jogo para os Intérpretes. Ao nomear os motivos, revelam-se conteúdos e conceitos (Função e Expressão); que são imediatamente compartilhados com o público. O Jogo em si tem um vocabulário básico que é facilmente compartiIhável. No entanto, à medida que cada jogo se desenvolve, ele também cria sua própria complexidade.

Nomear os conteúdos e refletir sobre os conceitos desdobrados é trabalhar a partir da concretude da dança, falando sobre movimento em termos de movimento e linguagem. Laban foi profundamente dedicado a essa questão ao longo de seu trabalho. Através dessas tríades, os Jogadores experimentam a complexidade dessas questões que envolvem a criação cênica. É um trabalho árduo aprender a nomear e abordar o movimento em seus termos; requer tempo, pesquisas e complexidade.

Trio traz para o Projeto Jogo Coreográfico uma outra maneira de lidar com a palavra, a palavra escrita, impressa, colorida como motivo ou como uma síntese de apreciação. Assim, é possível criar muitas motivações para os movimentos e apresentá-las por meio de palavras.

Como síntese dessas reflexões e compartiIhamento de experiências e ideias em movimento, arte, reflexão e produção de conhecimento, encerra-se esse texto recapitulando a importância de Laban e seu pensamento para a construção do panorama das Artes da Cena do século XXI, anunciando já no início do século $X X$ a necessidade de uma dança investigativa e independente com base nas pulsões individuais de cada artista diante de seu tempo. Movimento, transformação e mudança são princípios chaves para as danças dos dias de hoje e para incansavelmente não deixarmos de lutar por uma sociedade diferente, com mais humanidade, liberdade, igualdade de direitos e que respeite a natureza.

O Jogo Coreográfico é uma experiência que cruza as fronteiras entre a produção e a formação do artista do movimento, entre o artista e o público, viabilizando dinâmicas coletivas de coautoria que priorizam a colaboração para a criação de narrativas em conjunto. O Jogo Coreográfico é um convite ao relacionamento, uma utopia, é um espaço de sonho, uma ideia que investe na liberdade de imaginação.

\section{Referências}

BLOM, A.; CHAPLIN, L. The Intimate Act of Choreography. Pittsburg: University of Pittsburg, 1942.

HUIZINGA, J. Homo Ludens. O Jogo como Elemento da Cultura. São Paulo, Editora Perspectiva, 1995.

KERKHOVE, Marianne. (Org.). Dossier: Danse et Dramaturgie. In: Nouvelles de Danse. Bruxelles: Contredanse, 1997. 
LABAN, R. O Domínio do Movimento. São Paulo, Summus Editorial, 1978.

Una Vida para la Danza. México: Ríos y raíces, 2001.

LOPES, J. Coreodramaturgia: A dramaturgia do Movimento. Primeiro caderno pedagógico. Departamento de Artes Corporais/ Unicamp, 1998.

Recebido: 15/06/2020

Aceito: $24 / 08 / 2020$

Aprovado para publicação: 10/12/2020

Este é um artigo de acesso aberto distribuído sob os termos de uma Licença Crea- tive Commons Atribuição 4.0 Internacional. Disponível em: <http://creative commons.org/licenses/by/4.0>.

This is an open-access article distributed under the terms of the Creative Commons Attribution License 4.0 International. Available at: $<$ http://creative commons.org/licenses/by/4.0>.

Ce texte en libre accès est placé sous licence Creative Commons Attribution 4.0 International. Disponible sur: <http://creativecommons.org/licenses/by/4.0>. 